\title{
Integridade Científica e Académica em Portugal: Um Desígnio Nacional
}

\section{Scientific and Academic Integrity in Portugal: A National Enterprise}

João MASSANO $\ 1,2,3$, Maria Amélia FERREIRA ${ }^{3,4}$

Acta Med Port 2020 Jan;33(1):1-3 - https://doi.org/10.20344/amp.12930

Palavras-chave: Ética; Fraude; Integridade; Investigação; Má conduta; Plágio

Keywords: Ethics; Fraud; Integrity; Plagiarism; Research; Scientific Misconduct

Yoshihiro Sato dedicou-se à investigação na área da biologia óssea durante quase duas décadas e publicou dezenas de estudos demonstrando resultados de grande relevância clínica como, por exemplo, na prevenção das fraturas ósseas. Estes artigos acabaram por ser analisados em detalhe: ficou provado que Sato inventou sujeitos e fabricou dados para os estudos que publicou. Em consequência foram já retirados de publicação mais de 60 artigos da sua autoria. É um dos maiores escândalos de fraude académica conhecidos até à data. ${ }^{1}$

Inúmeras situações de fraude académica têm sido divulgadas em publicações científicas, como a Nature ou a Science, e em vários sítios eletrónicos (e.g. https://retractionwatch.com). A comunicação social tradicional tem também noticiado estas situações, com impacto junto da opinião pública. O reconhecimento e a divulgação cada vez mais frequente dos comportamentos fraudulentos de académicos das mais variadas áreas do conhecimento ilustra bem a extensão desta problemática. Este não é um fenómeno exclusivo da contemporaneidade, mas tem adquirido maior visibilidade nos últimos anos. ${ }^{1,2}$ Apesar de tudo, os casos que vieram ao conhecimento público representarão provavelmente apenas 'a ponta do icebergue'. A fraude académica acarreta importantes e complexos desafios para as instituições e elementos mais diretamente envolvidos na atividade científica, nomeadamente as equipas de investigação, as instituições académicas, os financiadores e as revistas científicas - mas tem também relevância para a sociedade como um todo.

A fraude académica, definida concisamente como a alteração deliberada da verdade científica, tem sido tradicionalmente classificada em falsificação, fabricação e plágio. ${ }^{3}$ No entanto existem outras formas de má conduta científica,,$^{2,3}$ menos valorizadas e de menor visibilidade, mas provavelmente mais frequentes e que também não podem ser esquecidas (Tabela 1) - por exemplo, qualquer um evocará facilmente o testemunho de situações em que os co-autores de determinados artigos nunca o deveriam ter sido, pela ausência de contributo intelectual relevante para os mesmos. ${ }^{4} \mathrm{O}$ caso clássico é o do 'chefe' que exige ser co-autor com base apenas no seu estatuto hierárquico.

Muitos académicos reconhecem que já incorreram em comportamentos fraudulentos, ${ }^{5}$ cujos custos económicos (e sociais) podem ser impressionantes. ${ }^{6}$ Para além do desperdício financeiro direto resultante da má conduta académica as implicações negativas são muito mais amplas para toda a sociedade, pois os resultados dos estudos científicos induzem frequentemente alterações em intervenções médicas ou simplesmente nos hábitos das pessoas em geral. A aplicação de resultados fraudulentos pode causar graves problemas de segurança nos doentes e na saúde pública de uma forma global. Imagine-se, por exemplo, as consequências desastrosas de estudos científicos fraudulentos que 'demonstrassem' a eficácia da prevenção da doença de Alzheimer através da interrupção do consumo de fruta e vegetais, ou a inutilidade dos antiagregantes plaquetários na prevenção secundária de eventos coronários!

Também a descrença nos cientistas e na investigação científica, produzida na opinião pública em consequência da divulgação mediática dos casos de fraude académica, contribui certamente para a desvalorização das opiniões científicas credíveis, e até para a proliferação da crença cega nas 'notícias falsas' (fake news) que atualmente abundam. A dimensão do impacto negativo da fraude académica na sociedade é difícil de calcular, mas é potencialmente catastrófico.

As instituições académicas e as revistas científicas que se vêm envolvidas nos casos de má conduta têm a obrigação de investigar e apurar os factos, produzindo as devidas consequências disciplinares ao nível institucional, e sobre as publicações, no caso das revistas. O Committee on Publication Ethics (COPE - http://www.publicationethics.org), organização idónea cujas recomendações são atualmente seguidas pelas revistas científicas de qualidade, preparou documentos orientadores que os Editores utilizam no decorrer da sua atividade, incluindo nos casos de fraude

1. Serviço de Neurologia e Unidade de Investigação. Centro Hospitalar Universitário de São João. Porto. Portugal.

2. Departamento de Neurociências Clínicas e Saúde Mental. Faculdade de Medicina. Universidade do Porto. Porto. Portugal.

3. Unidade de Investigação e Desenvolvimento Cardiovascular (UnIC). Faculdade de Medicina. Universidade do Porto. Porto. Portugal.

4. Departamento de Ciências da Saúde Pública e Forenses, e Educação Médica. Faculdade de Medicina. Universidade do Porto. Porto. Portugal.

$\triangle$ Autor correspondente: João Massano. jmassano@med.up.pt

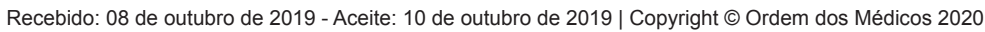


Tabela 1 - Integridade científica e académica: breve glossário (baseado na referência 3)

\begin{tabular}{ll}
\hline Termo & Definição \\
\hline Académico (substantivo) & $\begin{array}{l}\text { Pessoa que integra a comunidade de instituições de ensino, podendo desempenhar funções docen- } \\
\text { tes, de investigação ou administração. }\end{array}$
\end{tabular}

Autoria honorária (ou de oferta) Prática que conduz à nomeação de um co-autor num artigo para o qual este não contribuiu o suficiente para poder ser considerado justamente como tal.

Fabricação de dados

Invenção de experiências, dados (incluindo imagens e vídeos) ou outras informações relevantes e sua utilização como se fossem genuínos.

Falsificação de dados

Manipulação injustificada de dados (incluindo imagens e vídeos) ou equipamentos de investigação ou de conteúdo educacional com a intenção de causar uma impressão enganadora.

Fraude $\quad$ Mentira intencional para assegurar um ganho.

Integridade académica

Observância de princípios, práticas e padrões éticos e profissionais pelas instituições e indivíduos no decurso das atividades pedagógicas, docentes e de investigação científica.

Má conduta (ou má prática) académica

Plágio

Retração de publicação
Qualquer ação, tentada ou completada, que comprometa a integridade académica e que pode resultar em vantagem académica injusta, ou em desvantagem para qualquer outro membro da comunidade académica ou para a sociedade em geral.

Ato de publicar ou submeter para publicação material (texto, imagem, vídeo) da autoria de outrem como se este fosse da sua autoria (sem o devido reconhecimento da fonte original).

Ato de remover artigo científico do registo de publicação pelo facto de os resultados não terem sido considerados fidedignos ou porque os autores incorreram em má conduta académica. As revistas identificam os artigos nesta situação em bases de dados eletrónicas e nas edições impressas, de forma a alertar a comunidade académica para os problemas encontrados. académica. As consequências podem ir da 'expressão de preocupação' editorial, como aconteceu recentemente na Acta Médica Portuguesa, ${ }^{7}$ até à retração dos artigos já publicados e publicitação da má-conduta académica. A referida iniciativa editorial da Acta Médica Portuguesa culminou na retracção do artigo visado.

Vários países perceberam há muito a importância desta questão, pelo que criaram políticas e estruturas que lidam especificamente com este problema - o que não tem acontecido no nosso país. Por isso, parece-nos importante implementar em Portugal uma estratégia integrada de atuação em duas áreas nucleares, distintas e complementares:

1. Educação e prevenção: todos os indivíduos envolvidos na atividade académica devem frequentar programas educacionais formais acerca da integridade académica. A abordagem desta temática deve ser consistente no ensino superior a todos os níveis, incluindo nos programas de pós-graduação (mestrado e doutoramento). Por outro lado, as instituições e grupos de investigação devem fomentar a criação de um ecossistema propício, em que as lideranças demonstrem preocupação e atenção em relação à integridade científica. Não podem ser deixadas dúvidas quanto à total falta de tolerância em relação à má conduta académica, mas sempre mostrando total abertura quanto à análise deste assunto e para a discussão de situações concretas.

2. Supervisão e ação disciplinar: devem existir pro- cedimentos bem definidos que orientem a investigação de suspeitas e denúncias de má conduta em todas as instituições com atividade científica. Deve ser constituído um organismo dedicado que lide com este tipo de situações, inserido na orgânica institucional permanente. É importante que estas comissões possam investigar com independência, transparência e celeridade todas as suspeitas, mantendo a confidencialidade exigida pelas circunstâncias, e propondo depois aos órgãos executivos e disciplinares das instituições as ações a tomar.

Mas é preciso fazer mais: é fundamental criar uma organização de âmbito nacional, na dependência direta do Governo, que possa coordenar as ações preventivas e actuar nos casos suspeitos de fraude académica em todas as áreas do conhecimento. Esta Agência Nacional da Integridade Científica e Académica deve ter o poder e os meios para investigar estes casos, tal como sucede noutros países europeus e nos Estados Unidos (e.g. The Office of Research Integrity, https://ori.hhs.gov). A Agência deve ser uma iniciativa inter-ministerial, envolvendo os Ministérios da Ciência, Tecnologia e Ensino Superior e o da Saúde, exigindo-se uma liderança forte e idónea. A sua estrutura deve envolver representantes de organizações relevantes neste âmbito, como a Fundação para a Ciência e a Tecnologia e o Conselho de Reitores das Universidades Portuguesas. Esta Agência será também responsável por 
emitir documentos de âmbito nacional que promovam a atividade científica de acordo com os mais elevados padrões de conduta ética e integridade. Por outro lado, definirá a metodologia dos processos de investigação das suspeitas de fraude académica em Portugal, determinará as suas consequências, e auxiliará a atividade das comissões que lidam localmente com estas questões. Neste âmbito, há variados documentos nacionais e internacionais que podem ser referências preciosas..$^{3,8-12}$

Finalmente, será também importante refletir sobre as consequências judiciais e criminais decorrentes da fraude académica. Este é, porventura, um debate mais complexo

\section{REFERÊNCIAS}

1. Else $H$. What universities can learn from one of science's biggest frauds. Nature. 2019;570:287-8.

2. Gross C. Scientific misconduct. Annu Rev Psychol 2016;67:693-711.

3. Tauginiene L, Gaižauskaite I, Glendinning I, Kravjar J, Ojsteršek M, Ribeiro L, et al. Glossary for academic integrity. ENAI Report $3 G$. [consultado 2019 nov 08]. Disponível em: http://www.academicintegrity. eu/wp/wp-content/uploads/2018/02/GLOSSARY_final.pdf.

4. International Committee of Medical Journal Editors. Recommendations for the Conduct, Reporting, Editing, and Publication of Scholarly work in Medical Journals. December 2018. [consultado 2019 nov 08]. Disponível em: http://www.icmje.org/icmje-recommendations.pdf.

5. Pupovac V, Fanelli D. Scientists admitting to plagiarism: a meta-analysis of surveys. Sci Eng Ethics. 2015;21:1331-52.

6. Gammon E, Franzini L. Research misconduct oversight: defining case costs. J Health Care Finance. 2013;40:75-99.

7. Villanueva T. Editorial expression of concern. Acta Med Port. 2019;32:329.

8. National Academies of Sciences, Engineering, and Medicine. Fostering e controverso, que terá de envolver necessariamente os órgãos de soberania com poder legislativo, e deve colher o contributo da referida Agência Nacional e de outras partes interessadas.

Vemos demasiadas vezes a nossa sociedade e as nossas instituições reagirem aos problemas, em vez de promoverem a sua prevenção e resolução de forma atempada e eficaz. Por outro lado, a atitude contemplativa perante um problema que se sabe existir é perigosa e inaceitável. A integridade académica exige ação imediata em Portugal. Tempus fugit!

Integrity in Research. Washington, DC: The National Academies Press 2017. [consultado 2019 nov 08]. Disponível em: https://download.nap. edu/cart/download.cgi?record_id=21896.

9. Khajuria A, Agha R. Fraud in scientific research - birth of the Concordat to uphold research integrity in the United Kingdom. J R Soc Med. 2014;107:61-5.

10. Forsberg EM, Anthun FO, Bailey S, Birchley G, Bout H, Casonato C, et al. Working with Research Integrity - Guidance for Research Performing Organisations: The Bonn PRINTEGER Statement. Sci Eng Ethics. 2018;24:1023-34.

11. ALLEA - All European Academies. The European Code of Conduct for Research Integrity - Revised Edition. Berlin, 2017. [consultado 2019 nov 08]. Disponível em: https://allea.org/code-of-conduct/.

12. Carvalho AS, em nome do Conselho Nacional de Ética para as Ciências da Vida. Integridade na Investigação Científica - Recomendação. Lisboa, 2018. [consultado 2019 nov 08]. Disponível em: http://www. cnecv.pt/admin/files/data/docs/1523888172_IntegridadeCNECV2018. pdf. 